\title{
Assessment of $\mathrm{ABO}$-rhesus blood groups and hemoglobin concentrations of sickle cell disease pregnant women at booking in Nigeria
}

\begin{abstract}
Background: Chronic anemia in SCD during pregnancy could lead to a cascade of maternal and fetal complications. The aim of this study is to assess the various types of $\mathrm{ABO}$ blood groups of pregnant $\mathrm{SCD}$ women at booking and the severity of anemia. The outcome of this study will help in making recommendations of $\mathrm{ABO}$ blood types most suitable to improve the quality of life of SCD patients. This may contribute to guideline for safe blood transfusion in SCD.

Methodology: This was a-ten-year retrospective study of all registered SCD pregnant women seen at the antenatal clinic of Braithwaite Memorial Specialist Hospital (BMSH) Port Harcourt (January 2004- December 2013). Data on gestational age, Hemoglobin (HB) electrophoretic pattern, HB concentration and blood group were obtained at booking clinic. Data were analysed using Epi-info version 7.02 by WHO, Geneva Switzerland and CDC, USA.

Result: A total of $52 \mathrm{Hb}$ SS pregnant women were seen during the study period. The average booking trimester was the $2^{\text {nd }}$ trimester. $94.2 \%(49)$ were anemic $(<11.0 \mathrm{~g} / \mathrm{dl})$ while $5.8 \%(3)$ were non anemic $(\geq 11 \mathrm{~g} / \mathrm{dl}) .27 .0 \%, 9.6 \%$ and $61.5 \%$ were A, B and O rhesus D positive blood groups respectively. No AB blood group was recorded from this study. The $\mathrm{O}$ rhesus $\mathrm{D}$ positive blood group was significantly more prone to anemia [30 (61.2\%)] than other ABO blood groups $\left(\mathrm{X}^{2}=50.37 ; 0.001\right) .20 \%(1 / 5)$ of $\mathrm{B}$ rhesus $\mathrm{D}$ positive and $6.3 \%$ $(2 / 32)$ of $\mathrm{O}$ rhesus D positive patients were non-anemic. All A rhesus D positive blood were anemic. The highest prevalence of A rhesus D positive blood group (37.5\%) was in $2^{\text {nd }}$ trimester, that of $\mathrm{B}(20 \%)$ and $\mathrm{O}(66.7 \%)$ rhesus D positive blood groups were in $1^{\text {st }}$ and $3^{\text {rd }}$ trimesters respectively.
\end{abstract}

Conclusion: Although most SCD pregnant women in this region are $\mathrm{O}$ rhesus D positive blood groups, B rhesus D positive blood group patients appear to be less susceptible to anemia. There is need to carry out more elaborate study on this blood group.
Volume 5 Issue 2 - 2017

\author{
Ogbonna Collins Nwabuko,2 Dorathy \\ Adaunwa Okoh ${ }^{3}$ \\ 'Department of Hematology, Federal Medical Center, Nigeria \\ ${ }^{2}$ Department of Hematology and Immunology, Abia State \\ University, Nigeria \\ ${ }^{3}$ Braithwaite Memorial Specialist Hospital, Port Harcourt, \\ Nigeria
}

\begin{abstract}
Correspondence: Ogbonna Collins Nwabuko, Department of Hematology and Blood Transfusion, Federal Medical Center,Aba Road, PMB 700I, Umuahia, Abia State, Nigeria, Tel +234 803704 6537,Email ogbollins2002@yahoo.com, collins.nwabuko@waldenu.edu
\end{abstract}

Received: June 19,2017 | Published: August 30, 2017

Keywords: SCD, pregnancy, ABO, rhesus D blood groups

Abbreviations: BMSH, braithwaite memorial specialist hospital; SCD, sickle cell disease; HB, hemoglobin; vWF, von willebrand factor; SCA, sickle cell anemia

\section{Introduction}

Sickle cell disease (SCD) is a major public health challenge globally. SCD in pregnancy accounts for $0.14-0.2 \%$ of all pregnancies in Niger Delta Nigeria. ${ }^{1,2}$ As a result of the sickling tendency of the red blood cells in this condition, they tend to undergo premature destruction in reticuloendothelial cells and this leads to anemia. Anemia in SCD (with or without pregnancy) could be devastating and may lead to frequent hospitalization, transfusion dependence, intrauterine growth retardation, low birth weight, still birth and maternal death just to mention a few. ${ }^{3-5}$ The ABO blood group system is the most important determinant of transfusion compatibility out of over 400 blood group antigens that are known. The ABO system is a group of carbohydrate antigens defined by the terminal saccharide moiety that attaches to the sub-terminal galactose moiety. The sub-terminal galactose, in association with terminal $\mathrm{N}$-acetyl galactosamine gives rise to blood group A, whereas addition of terminal galactose or fructose moiety gives rise to $\mathrm{B}$ or $\mathrm{O}$ blood group respectively. Individuals who express both $\mathrm{A}$ and $\mathrm{B}$ sugar moieties are group $\mathrm{AB}$ whereas those who express neither of these sugars are group $\mathrm{O}$. The $\mathrm{H}$ antigen remains unmodified in group $\mathrm{O}$ individuals and for this reason some authors refer $\mathrm{ABO}$ antigen system as the $\mathrm{ABH}$ system. ${ }^{6}$ The $\mathrm{ABO}$ gene locus is on chromosome 9. The A and B genes encode transferase enzymes that covalently attach the specific terminal saccharide moiety to the sub terminal galactose.

In the Caucasian U.S. blood donor population, blood group $\mathrm{O}$ is the most common (45\%), followed by group A (40\%), group B (11\%), and group $\mathrm{AB}(4 \%)$. In the African Americans, the order of frequency is similar, but there are fewer group A (27\%) and more group B (20\%) in this population. ${ }^{7,8}$ Blood group $\mathrm{O}$ most likely evolved in Africa because it provides a selective advantage against severe malaria. Individuals with blood group $\mathrm{O}$ have lower levels of von Willebrand factor (vWF), which must be taken into cognizance in the diagnosis of type 1 von Willebrand disease. Conversely, non-group O individuals have a greater risk of venous thromboembolism attributable to the higher levels of vWF and FVIII. ${ }^{6}$ Clinically, the Rhesus blood group system is second in importance to the $\mathrm{ABO}$ system. It is a collection 
of 50 different antigens encoded by two genes, designated RHD and RHCE on chromosome 1p34-36. Rh antigens are proteins and unlike the $\mathrm{ABO}$ system, antibodies to Rh antigens rarely are present unless a person has been immunized by pregnancy, transfusion, or stem cell transplantation. Rhesus incompatibility is therefore necessary because of its high immunogenicity and potential role in hemolytic disease of the newborn and delayed hemolytic transfusion reaction. ${ }^{6}$

Red cell transfusion plays significant therapeutic role in SCD. It may be used to treat acute complications and to prevent chronic complications. For example, the morbidity and mortality of vasoocclusive crises, cerebrovascular accident ${ }^{9}$ surgery,${ }^{10}$ events related to anemia ${ }^{11}$ and acute chest syndrome ${ }^{12}$ have been reported to be reduced by transfusion therapy. Red cell transfusion can be lifesaving but carry a risk of adverse effects including death. Many hazards, such as risk of alloimmunization, autoimmunization, acute hemolytic transfusion reaction and delayed hemolytic transfusion reaction (DHTR), are amplified in SCD. These adverse effects culminate to anemia in the patient. Alloimmunization is a serious common complication in sickle cell anemic (SCA) patients. It presents as an immunological response by recipient against "foreign" non-self antigens that may follow an erythrocyte transfusion and result in destruction of transfused erythrocyte. It results in difficulty obtaining compactible blood, delayed transfusion reactions and occasional life-threatening events. ${ }^{13,14}$ The risk of alloimmunization in patients with SCA has been reported to range from 4-40 percent. ${ }^{13,15-18}$ Many best practices to minimize adverse effects of red cell transfusion remain under investigation. This formed part of the basis for this study. This study was aimed at assessing the various ABO-Rhesus blood groups in SCD pregnant women, their vulnerability to anemia and suitability for safe blood transfusion. The outcome of this study will help in decisionmaking of the choice of blood group most suitable for safe blood transfusion in SCD patients at emergency or during pregnancy.

\section{Materials and methods}

This was a retrospective study of antenatal care patients seen at the Braithwaite Memorial Specialist Hospital (BMSH) in Port Harcourt, Rivers State, Nigeria. The study was carried out from 2004 to 2013 with a total of 52 SCD pregnant women seen during the study period. Ethical clearance for the study was obtained from the Ethical Committee of the BMSH. The data were obtained from laboratory registers where records of pregnant women and results of investigations done at booking were kept within the period. Demographic data, ABO/Rhesus blood groups, hemoglobin concentration at booking and genotype were among the clinical information obtained at the ante-natal clinic. The data obtained were entered and analyzed using Epi-info statistical software version 7.02 by the WHO, Geneva, Switzerland, and CDC, USA. The student's t-test was used to determine the significant differences between the mean values. $\mathrm{P}=0.05$ was set as the level of statistical significance.

\section{Results}

A total of 52 SCD pregnant women with a mean age of 27 were seen at the antenatal clinic of BMSH, Port Harcourt, between January 2004 and December 2013, out of which 14(27.0\%) were A rhesus D positive, $5(9.6 \%$ ) were $\mathrm{B}$ rhesus $\mathrm{D}$ positive, $32(61.5 \%)$ were $\mathrm{O}$ rhesus $\mathrm{D}$ positive and $1(1.9 \%) \mathrm{O}$ rhesus $\mathrm{D}$ negative blood groups. There was no $\mathrm{AB}$ rhesus blood group from this study. The $\mathrm{O}$ blood group had the highest prevalence $(63.4 \%)$ while the $\mathrm{AB}$ blood group was the least $(0.0 \%)$ from this study. The gene frequency with respect to $\mathrm{ABO}$ system can be shown as $\mathrm{O}>\mathrm{A}>\mathrm{B}>\mathrm{AB} .98 .1 \%$ (51) of the women were rhesus D positive blood group while $1.9 \%$ (1) was rhesus D negative blood group. The A rhesus D positive blood group had the least mean hemoglobin concentration $(7.50 \mathrm{~g} / \mathrm{dl})$ while $\mathrm{B}$ rhesus D positive group had the highest hemoglobin concentration $(8.24 \mathrm{~g} / \mathrm{dl})$. However the difference was not statistically significant $(p>0.05)$ (Table 1$)$. The prevalence of anemia was $94.2 \%(49)$, out of which $12.2 \%$ had mild anemia $(\mathrm{HB}=10.0-10.9 \mathrm{~g} / \mathrm{dl}), 65.3 \%$ had moderate anemia $(\mathrm{HB}=7.0$ $9.9 \mathrm{~g} / \mathrm{dl}$ ) and $22.5 \%$ had severe anemia $(\mathrm{HB}<7.0 \mathrm{~g} / \mathrm{dl})$ (as illustrated in Table 2). $5.8 \%$ (3) were non-anemic $(\mathrm{HB} \geq 11.0)$. The $\mathrm{O}$ rhesus $\mathrm{D}$ positive blood group had a statistically significant higher anemia $(61.2 \%)$ than other blood groups $\left(\mathrm{X}^{2}=50.37 ; \mathrm{P}=0.001\right)$ (Table 3). $20 \%$ $(1 / 5)$ of the $\mathrm{B}$ rhesus D positive and $6.3 \%(2 / 32)$ of the $\mathrm{O}$ rhesus $\mathrm{D}$ positive women were non-anemic. All the A rhesus $\mathrm{D}$ positive and $\mathrm{O}$ rhesus D negative blood groups were anemic (Table 4). The highest prevalence of A rhesus D positive blood group $(37.5 \%)$ was recorded in the $2^{\text {nd }}$ trimester, while that of $\mathrm{B}(20 \%)$ and $\mathrm{O}(66.7 \%)$ rhesus $\mathrm{D}$ positive blood groups were in $1^{\text {st }}$ and $3^{\text {rd }}$ trimester respectively. The only O rhesus D negative blood group $(5.56 \%)$ was in the $3^{\text {rd }}$ trimester (Figure 1).

Table I ABO Blood Groups Pattern and Mean Hemoglobin Concentrations of SCD Pregnant Women at Booking

\begin{tabular}{|c|c|c|c|c|}
\hline \multirow{2}{*}{ Blood group } & \multicolumn{3}{|l|}{ Frequency $n(\%)$} & \multirow{2}{*}{ Mean hemoglobin concentration(g/dl) } \\
\hline & SCD Pregnant women & Rhesus D positive & Rhesus D negative & \\
\hline A & $14(27.0)$ & $14(27.0)$ & - & 7.5 \\
\hline B & $5(9.6)$ & $5(9.6)$ & - & 8.24 \\
\hline$A B$ & $0(0.0)$ & 0 & - & - \\
\hline O & $33(63.5)$ & $32(61.5)$ & $\mathrm{I}(\mathrm{I} .9)$ & 8.1 \\
\hline Total & $52(100.0)$ & $5 I(98.1)$ & $\mathrm{I}(\mathrm{I} .9)$ & \\
\hline
\end{tabular}

$\mathrm{ABO}$ Blood group in the descending order of prevalence: $\mathrm{O} \mathrm{rh}^{+}>\mathrm{A} \mathrm{rh} \mathrm{CB}^{+}>\mathrm{O} \mathrm{rh}^{-}$ 
Table 2 Prevalence and grade of anemia in SCD pregnant women at booking

\begin{tabular}{lll}
\hline Anemia/Grade $\mathbf{H B}(\mathrm{g} / \mathrm{dl})$ & Frequency $(\mathbf{n})$ & Percentage(\%) \\
\hline$<11.0$ & 49 & 94.2 \\
$>11.0$ & 2 & 5.8 \\
Grades of anemia & & \\
Mild(I0.0-10.9) & 6 & 12.2 \\
Moderate(7.0-9.9) & 32 & 65.3 \\
Severe $(<7.0)$ & $\mathrm{II}$ & 22.5 \\
\hline
\end{tabular}

Table 3 Chi square of $A B O$ blood groups of SCD pregnant women with respect to anemia at Booking

\begin{tabular}{lll}
\hline Blood group & $\begin{array}{l}\text { Frequency of } \\
\text { anemia } \mathbf{n}(\%)\end{array}$ & Chi square(p-value) \\
\hline A Rhesus D Positive & $14(28.56)$ & \\
B Rhesus D Positive & $4(8.20)$ & $50.37(0.001)^{*}$ \\
O Rhesus D Positive & $30(61.20)$ & \\
O Rhesus Negative & $\mathrm{I}(2.04)$ & \\
Total & $49(100.0)$
\end{tabular}

NB: Women with the Blood group $\mathrm{O}^{+}$have statistically significant highe anemia (6I.2\%) than women with other blood groups $\left(X^{2}=50.37 ; 0.00 I\right)$.

Table 4 Pattern of anemia in the ABO blood groups of the SCD Pregnant women

\begin{tabular}{lll}
\hline Blood group & Anemic(n) & Non-anemic(n) \\
\hline A Rhesus Positive & $\mathrm{I} 4(27.0)$ & $0(0.0)$ \\
B & $5(9.6)$ & $\mathrm{I}(33.33)$ \\
O & $32(61.5)$ & $2(66.67)$ \\
O Rhesus Negative & $\mathrm{I}(1.9)$ & $0(0.0)$
\end{tabular}

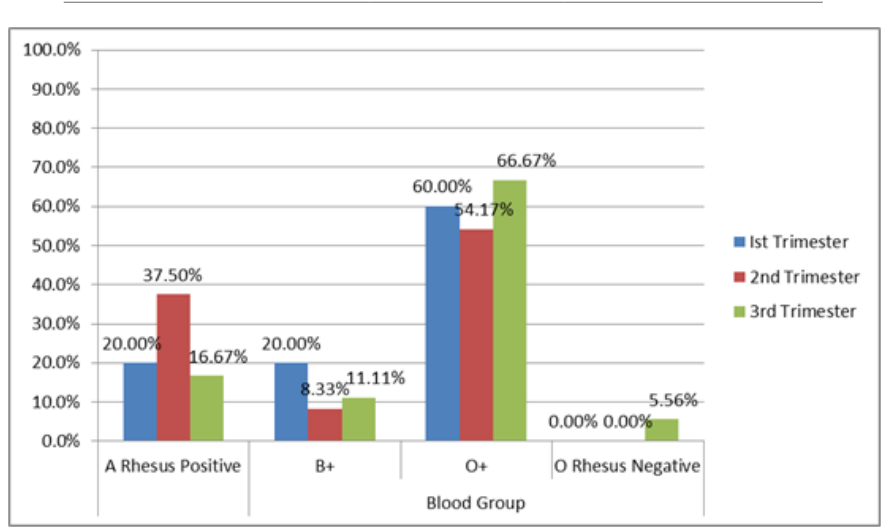

Figure I Prevalence of $A B O$ blood groups of SCD pregnant women at different trimesters.

\section{Discussion}

This study showed that $27 \%$ of sickle cell disease pregnant women who booked at the ante-natal clinic were A rhesus D positive. This value was in keeping with previous studies in Nigeria, ${ }^{19,20}$ relatively higher than that in India, ${ }^{21}$ but lower than the study in Caucasians. ${ }^{7}$ However the $\mathrm{O}$ rhesus D positive blood group (61.5\%) was relatively higher than that in both Blacks (55\%) and Caucasians (45\%). ${ }^{8}$ The frequency of B blood group was significantly lower than that recorded by Mondal et al. ${ }^{21}(34.9 \%)$ in India in which a preponderance of allele B of ABO blood group over allele A (22.7\%) was observed. Similar higher B blood group was recorded by Erhabor et al. ${ }^{19}(23.6 \%)$ in Nigeria, however, unlike the Indian study, the allele A was more preponderant. In general, the $\mathrm{B}$ rhesus $\mathrm{D}$ positive blood group prevalence $(9.6 \%)$ from this study was more in keeping with that of Caucasians (11\%) than that of the Black $(20 \%)$ population. ${ }^{6}$ This study showed that $\mathrm{O}$ blood group recorded the highest prevalence compared to other $\mathrm{ABO}$ blood groups in the SCD pregnant women. Previous studies in Asian, ${ }^{21}$ African ${ }^{19,20}$ and American continents had shown $\mathrm{O}$ blood group as the commonest $\mathrm{ABO}$ blood group. This tallies with both Caucasians and African American donor blood population statistics where $\mathrm{O}$ rhesus $\mathrm{D}$ blood group is the commonest $\mathrm{ABO}$ blood group. The $\mathrm{O}$ blood group recorded from this study was higher $(63.4 \%)$ than $\mathrm{O}$ blood groups from previous studies. ${ }^{19,21}$ This shows that SCD pregnant women tend to have very high prevalence of $\mathrm{O}$ blood group compared to a normal population. This study also showed that the ABO pattern of distribution in SCD pregnant women tends to depict a mixture of the Caucasian and Black blood donor populations. There was no $\mathrm{AB}$ blood group $(0.0 \%)$ recorded in this study. Previous studies on ABO blood group had shown that AB blood group is the least prevalent ranging from $3.8 \%-6.68 \%{ }^{19,21}$ However, this report was for the general population as there was no previous study on the ABO blood group pattern of SCD pregnant women in this region. Although limitation by the small study population may be contributory, it cannot be ruled out completely that the $\mathrm{AB}$ blood group is rare in SCD pregnant women. There is therefore a shift in gene frequencies with respect to $A B O$ system from $O>B>A>A B$ in Asian continent to $\mathrm{O}>\mathrm{A}>\mathrm{B}>\mathrm{AB}$ in African continent from previous studies. ${ }^{6,719-21}$ This study showed that $98.1 \%$ of the SCD pregnant women were Rhesus D positive while $1.9 \%$ was rhesus D negative. This value was in keeping with $96.7 \%$ recorded by Ukaejiofor et al..$^{22}$ in Nigeria, 94\% recorded by Mwangi et al. ${ }^{23}$ in Kenya, $96.6 \%$ by Pramanik et al. ${ }^{24}$ in Nepal and $97.7 \%$ by Mondal et al. ${ }^{21}$ in India. This was in keeping with the statistics of Rhesus blood group of Black donor population where rhesus $\mathrm{D}$ positive blood group is more prevalent than the rhesus $\mathrm{D}$ negative blood group. The $1.9 \% \mathrm{RhD}$ negative blood group recorded in this study was lower than the prevalence of not less than $14 \%$ observed in studies among Caucasians. ${ }^{25,26}$ The $\mathrm{Rh}$ blood group system is the most polymorphic of the human blood groups, consisting of at least 45 independent antigens and, next to $\mathrm{ABO}$, is the most clinically significant in transfusion medicine. ${ }^{6,19}$ Therefore, the low prevalence of $\mathrm{Rh} \mathrm{D}$ negative blood group among SCD pregnant women serves a beneficial purpose as there will be less Rh-D incompatibility diseases among this study population when compared to their western counterparts.

This study shows very high prevalence of Blood group $\mathrm{O}$ with low Rh D negative and rare AB blood groups among SCD pregnant women. Unlike in previous studies ${ }^{19,21}$ where the high frequency of O blood group (universal blood donor) are of advantage in terms of availability of blood during emergency, that of SCD pregnant women would not provide such advantage as SCD patients' blood fall within the category of permanently deferred blood as they are ineligible donors. Hence, they cannot donate but can only receive blood. In addition, there is a need to explore the level of hemolysin in the plasma of blood group O SCD patients in order to ascertain if they will benefit more on antibody-typed group- specific blood transfusion. The scarcity of $\mathrm{AB}$ blood group among our study population means that much caution is needed during grouping and cross-matching 
blood for transfusion to SCD patients especially during pregnancy as there are rare universal recipients in this population of patients. The advocacy in this case will be more of group-specific blood transfusion in order to avoid adverse blood transfusion reaction.

As a result of limited therapeutic options in the management of sickle cell disease, red cell transfusion has become very essential in the treatment of sickle cell disease and its complications. Transfusion therapy for sickle cell disease is limited by the development of antibodies to foreign red cell, a condition known as alloimmunization. There is high rate of alloimmunization to $\mathrm{RBC}$ antigens among patients with sickle cell disease. The reasons for the high rates, though poorly understood, are attributed to higher intrinsic immune responsiveness to blood group antigens and racial differences between the blood donor and recipient populations. ${ }^{20}$ This adverse effect could be minimized by proper $\mathrm{ABO} / \mathrm{Rh}$ blood grouping and red blood cell genotyping at booking in the antenatal clinic. The prevalence of anemia in SCD pregnant women from this study was $94.2 \%$. Anemia in this context is defined based on World Health Organization (WHO) definition of $<11.0 \mathrm{~g} / \mathrm{dl}$ in the $1^{\text {st }}$ and $3^{\text {rd }}$ trimesters of gestation. ${ }^{21}$ This is higher than the WHO global prevalence rate of $57.1 \%$ in a general population, ${ }^{22}$ but lower than an earlier reported prevalence rate of $100 \%$ in a similar study by Okoh et al. ${ }^{5}$ However, in that same study, the prevalence rates of anaemia in Hemoglobin AA and AS pregnant women were 69.1 and $71.4 \%$ respectively. Most $(87.8 \%)$ of the SCD pregnant women presented moderate-severe grades of anemia whereas in the normal population (non-SCD population) the pattern was mildmoderate. ${ }^{5}$ The moderate-severe anemia in this context could be due to the chronicity of anemia in sickle cell disease coupled with the increase demand for blood during pregnancy. The $\mathrm{B}$ rhesus $\mathrm{D}$ positive blood group had the highest Hemoglobin concentration $(8.24 \mathrm{~g} / \mathrm{dl})$ while the $\mathrm{A}$ Rh $\mathrm{D}$ positive group recorded the least mean hemoglobin concentration of $7.5 \mathrm{~g} / \mathrm{dl}$. Although there is a dearth of data on the hemoglobin concentration of the various blood groups of SCD patients in pregnancy, this study has shown a gradual decrease in hemoglobin concentration as you move from Blood group B, O and A such that the frequency pattern can be shown as $\mathrm{B}>\mathrm{O}>\mathrm{A}$. In addition to recording the highest hemoglobin concentration, $20 \%$ of the B blood group SCD pregnant women were non-anaemic. The reason for blood group B less susceptibility to anaemia is not well understood. However, possible postulations from this study could be that the anti-A natural antibody expressed by blood group B is more stable and probably less prone to hemolysis compared to other natural antibodies expressed by the $\mathrm{ABO}$ system. It could also be that the terminal saccharide moiety (carbohydrate antigen-galactose in this case) that gives rise to blood group B may be more stable to degradation or sickling compared to that of other $\mathrm{ABO}$ system in SCD. Other possible reason could be due to the fact that most of the blood group B SCD pregnant women booked at the first trimester, and so the recorded higher hemoglobin concentrations compared to other ABO blood groups which booked mainly at the second and third trimesters. There is a need for further collaborative study on this note in a larger population size of SCD patients.

\section{Conclusion}

The assessment of ABO-Rhesus blood groups of a cohort of SCD pregnant women showed a high prevalence of $\mathrm{O}$ rhesus $\mathrm{D}$ positive blood group with rare $\mathrm{AB}$ and Rhesus negative blood groups. As a result of this, they may be more prone to $\mathrm{ABO}$ alloimmunization than rhesus incompatibility disease of the newborn. Hence, there is a need for proper ABO-Rhesus blood grouping and red blood cell genotyping at booking in ante-natal clinic. In order to ensure safe blood transfusion for prospective recipients, donors' blood should be group-specific and routine hemolysin testing should be carried out on all group $\mathrm{O}$ blood samples to allow those with high titre of hemolysin to be reserved specifically for group $\mathrm{O}$ patients so as to reduce the risk of blood transfusion reaction. Although most of the SCD pregnant women were moderately anemic, B rhesus D positive blood group appears to be less susceptible to anemia.

\section{Acknowledgements}

The authors wish to thank the management and the departments of Pathology and Hematology of BMSH, Port Harcourt, Rivers State, Nigeria and Federal Medical Center, Umuahia, Abia State, Nigeria, for creating enabling environment for this research work.

\section{Conflict of interest}

The authors report no conflict of interest in this work.

\section{References}

1. Ugboma HA, George IO. Sickle cell disease in pregnancy: maternal and fetal outcome in Port Harcourt, Nigeria. $\mathrm{Br} J$ Med Med Res. 2015;7(1):40-44.

2. Nwabuko OC, Okoh DA, Iyalla C, et al. Prevalence of sickle cell disease among pregnant women in a tertiary health center in south-south Nigeria. Sub-Saharan Afr J Med. 2016;3(3):132-136.

3. Graham RS, Luana LL, Mark C, et al. Outcome of pregnancy in homozygous sickle cell disease. Am Coll Obstet Gynecol. 2004;103(6):1278-1285.

4. World health organization. The prevalence of anemia in women: a tabulation of available information. Epidemiology in pregnancy. 2nd ed. USA: WHO/MCH/MSM; 1992. 100 p.

5. Okoh DA, Iyalla $\mathrm{C}$, Omunakwe $\mathrm{H}$, et al. A retrospective study of the prevalence of anaemia in pregnancy at booking in Niger Delta, Nigeria. J Obstet Gynaecol. 2016;36(5):594-597.

6. Karen Quillen, Suzanne Backdash. Transfusion medicine. In: Mccrae KR editors. American Society of Hematology Self-Assesment program. 5th ed. Richmond, USA: Cadmus Communication; 2013. p. 285-320.

7. Anstee DJ. Red cell grouping and the future of pretransfusion testing. Blood. 2009;114(2):248-256.

8. Avent ND. Large-scale blood group genotyping-clinical implications. $\mathrm{Br}$ J Haematol. 2009;144(1):3-13.

9. Russell MD, Goldberg HI, Reis L. Transfusion therapy for cerebrovascular abnormalities in sickle cell disease. J Pediatr. 1976;88:382-387.

10. Janik J, Seeler RA. Perioperative management of children with sickle hemoglobinopathy. J Pediatr Surg. 1980;15(2):117-120.

11. Piomelli S. Chronic transfusion in patients with sickle cell disease: indications and problems. Am J Pediatr Hematol Oncol. 1985;7(1):5155.

12. Davies SC, Luce PJ, Win AA, et al. Acute chest syndrome in sickle cell disease. Lancet. 1984;1:36-38.

13. Orlina AR, Unger PJ, Koshy M. Post-transfusion alloimmunization in patients with sickle cell disease. Am J Hematol. 1978;(2):101-106.

14. Chaplin H, Cassell M. The occasional fallibility of in vitro compactibility tests. Transfusion. 1962;2:375-384.

15. Brumfield CG, Huddleston JF, DuBois LB, et al. A delayed hemolytic transfusion reaction after portal exchange transfusion for sickle cell disease in pregnancy, a case report and review of the literature. Obstet Gynecol. 1984;63:135-155. 
16. Sarnaik S, Schornack JL, Lusher JM. The incidence of development of irregular red cell antibodies in patients with sickle cell anemia. Transfusion. 1986;26(3):249-252.

17. Patten E, Patel S, Soto B, et al. Prevalence of certain clinically significant alloantibodies in sickle cell disease patients: sickle cell disease. Ann NY Acad Sci. 1989;565:443-445.

18. Blumberg N, Ross K, Avila E, et al. Should chronic transfusion be matched for antigens other than ABO and Rh(D)? Vox Sang. 1984;47(3):205-208.

19. Erhabor O, Adias TC, Jeremiah ZA, et al. Abnormal hemoglobin variants, $\mathrm{ABO}$, and Rhesus blood group distribution among students in the Niger Delta of Nigeria. Pathol Lab Med Int. 2010;2:41-46.

20. Akhigbe RE, Ige SF, Afolabi AO, et al. Prevalence of hemoglobin variants, $\mathrm{ABO}$ and rhesus blood groups in Ladoke Akintola University of Technology, Ogbomosho, Nigeria. Trends Med Res. 2009;4:24-29.

21. Mondal B, Maiti S, Biswas BK, et al. Prevalence of hemoglobinopathy, $\mathrm{ABO}$ and rhesus blood groups in rural areas of West Bengal, India Journal of Research in Medical science: The official journal of Isfahan University of Medical sciences. 2012;17(8):772-776.
22. Ukaejiofor EO, Okonkwo WC, Tagbar EN, et al. Blood transfusion in the tropics. ABO and Rhesus in a Nigerian population. Nigeria: Salem Press; 1996. p. 1-22.

23. Mwangi J. Blood groups distribution in an urban population of patient targeted blood donors. East Afr Med J. 1999;76(11):615-618.

24. Pramanik T, Pramanik S. Distribution of ABO and Rh blood groups in Nepalese medical students: a report. East Mediterr Health J. 2000;6(1):156-158.

25. Bergstrom S, Pereira C, Hagstrom U, et al. Obstetric implications of Rhesus antigen distribution in Mozambican and Swedish women. Gynecol Obstet Invest. 1994;38(2):82-86.

26. Cerny T, Fey MF, Oppliger R. Prevalence of the Rhesus-negative phenotype in Caucasian patients with small-cell lung cancer (SCLC). Int J Cancer. 2006;52(3):504-506. 